\title{
Edible Coating Base on Aloe Gel with Additives on Strawberry Fruit
}

\author{
Luh Suriati *, Ni Made Ayu Suardani Singapurwa \\ Department of Food Science and Technology, Warmadewa University, Denpasar, Indonesia \\ *Email: suryatiluh1@gmail.com
}

\begin{abstract}
The edible coating is biodegradable and sustainable packaging has come into attention since the past few decades as an effort to reduce packaging waste. On a landmark fruit, the edible application layer is used to reduce the occurrence of loss of moisture, improve appearance, acts as a barrier to the exchange of gases, as well as having functions as an antifungal and antimicrobial. In addition to extending shelf life can be eaten these many layers are used such as it does not endanger human health, can be eaten as well as easy to untangle nature. One of the natural ingredients that can be used such as a layer of edible is Aloe Vera. From the results obtained that the weight without warming treatment gel stored at cool temperatures is relatively constant, while to gel without or with the treatment of warming that is stored at room temperature a little decline. The reduction drastic invisible on the gel with the saved warming treatment in cold temperatures. Aloe gel good shaped pieces that are stored at room temperature has decreased the weight but that is stored on the cold temperatures are relatively stable. The aloe vera gel with warming and stored at cool temperatures until day 5 relatively stable, as seen from the variable weight shrinkage, color, $\mathrm{pH}$, viscosity, and moisture content. While the gel is stored at room temperature decrease began day 2. Aloe Vera gel should be stored at cool temperatures with a sealed container. The best characteristics of Aloe Vera gel that treatment with sorbitol can extend the shelf life strawberry fruit. edible coating base on Aloe gel can be applied at post-harvest handling fruits.
\end{abstract}

Keywords: edible coating, aloe vera, gel, strawberry

\section{Introduction}

Strawberry fruits are a source of vitamins, minerals, and fiber that has nutritional benefits which are very good for health. Public awareness of the importance of health and nutritional value of the food they consume that stimulated. This increase from a demand for high-quality fruit, i.e. have a good appearance, relatively durable, and not quickly wither and rot during storage. Various ways that can be done to maintain the quality and inhibiting damage to fruits among others by packaging, storage modification with low temperature, and applying preservatives such as the edible coating on the fruits [1]. Edible coating very potential to increase the shelf life of fruits due to the theoretical development edible coating will form a coating that is capable of acting as a barrier to prevent moisture loss, are permeable to certain gases, as well as controlling the migration of water-soluble components that could cause pigmentary changes and nutritional components in fruits. Besides, preservatives also act as antioxidants, which will suppress the reaction that occurs upon contact with oxygen, food, rays, heat and some metal to prevent the onset of rancidity and the emergence of black smudges on the food products.

The number of dangerous preservatives raises concerns on the public to use it, where the impact posed a very high risk of health. Improved power saves fruit using natural preservatives to avoid the effects of the chemicals are still very uncommon. Some natural ingredients containing the enzyme oxidase as an antioxidant can be used as edible coating particularly on direct fruit is eaten without peeling his skin and very quickly damaged fruit such as strawberries, grapes, yellow and so on. One of these natural ingredients is Aloe Vera. Aloe Vera useful part is the aloe vera gel 
obtained from the leaves of the parenchyma chain [2]. Aloe Vera gel can make layers such as wax so it will still keep the quality of Strawberry fruit leather. Beside that Aloe Vera gel also has several advantages including raw materials that are easily obtained, the process is simple, a short processing time.

Aloe Vera gel does not affect taste or flesh of the fruit, natural and safe for the environment. The content of Aloe Vera gel is very complex as polysaccharide, sugar reduction, tannins, organic acids, minerals, proteins etc [2]. Beside that Aloe Vera gel containing glucomannan which according to can keep humidity the skin of the fruit. Aloe Vera gel also contains a variety of compounds that are antimicrobial and bioactive can heal the wound so that the network deployment is expected in Aloe Vera gel as the edible coating was able to maintain the quality and prolong the save fruits.

The application of Aloe Vera gel as edible coating has been tried previously on the grapes with the use of Aloe Vera gel which is dissolved with water [3]. Applications edible coating with the use of basic ingredients polysaccharides widely used primarily on fruit and vegetables because it can act as a selectively permeable membrane against $\mathrm{CO}_{2}$ gas exchange and $\mathrm{O}_{2}$ so it can extend shelf life due to the respiration of fruits and vegetables is reduced.

Based on this needs to be done further research presumably about treatment type and concentration of the addition of a filler that is right against the physicochemical Aloe Vera gel characteristics so that it can keep the rheology Aloe Vera gel as edible the coating will be applied to the handling of post-harvest fruits especially strawberry. This research aims to study the characteristics of the Aloe Vera gel as edible coatings in terms of the type and concentration of the addition of fillers, that will be applied to the handling of post-harvest fruit strawberry so have time to save.

\section{Research Method}

The research was conducted in February - October 2019 at the Food Analysis Laboratory of Warmadewa University and the Laboratory Bioindustries of Udayana University. The tools used are digital scales, refractometer, spectral colorimeter CS-280, chiller, Viscometer NDJ8S, digital pH meter, oven, Probe sonicator Q125 misonic USA and Texture analyser. The material used is aloe vera plant obtained from the village of Taro Gianyar Bali. The strawberry fruit will be coated with an edible coating obtained from the village Panji Buleleng Bali. Additive materials of citric acid, ascorbic acid, potassium sorbate, and analytical materials acquired in Denpasar.

Research using Randomized Complete Design (RCD) with two factors and repeat 3 times. Factor 1: types of Fillers on Aloe Vera gel (P) consists of Ascorbic acid, potassium sorbat, and gliserol. Factor 2: Time of storage $0,3,6,9,12$ and 15 day (W). Each treatment was replicate as 2 times so that the retrieved 32 units of the experiment. Observations were made against shrink weights, changes color, texture, total dissolved solids, $\mathrm{pH}$. Aloe Vera gel is stabilized by heat treatment to menginaktifkan enzimnya, then added suitable additive treatment. Formulation of edible coating that incorporated of additive, applied in Strawberry fruit. The next observation was done to see the changes the quality of Strawberry fruit during storage

\section{Results and Discussion}

\subsection{Edible coating base on Aloe Gel}

Aloe Vera gel without the warming that is stored at room temperature on day 3 is already Brown, this is caused due to contact with oxygen so that reaction Browning. The leaves are processed shortly after the start of harvest occurs the decomposition matrix degradative gel, due to 
a natural enzyme reaction in the presence of oxygen [4]. Two hours after the extraction if the gel is exposed to air or light then the color of the gel will turn pink and the next will be darker [2]. The color change has little relation to the effectiveness and stability of the gel. Some of the products the user psychologically unable to accept the color change. Therefore, it is simple but efficient processing that needs to be developed. Aloe Vera gel by heating with open containers stored at room temperature more quickly change color (day 3) compared to the gel is stored at cold temperatures. This is because the aloe vera gel contains carbohydrates i.e. glucomannan and contact with oxygen as well as supported by room temperature storage spur change process colors [2]. On the oxidation of carbohydrates, usually, cause changes of color and flavor. The color change that occurs is usually Brown or Sorrel and can also be gray or yellow. The oxidation of carbohydrates by various types of enzymes such as peroxidase and catalase reaction often called Browning enzimatis. To prevent this reaction is usually done warming up for inactivate enzyme. Enzymatic Browning reaction depends on oxygen levels and the $\mathrm{pH}$ of the medium.

The degree of acidity of the aloe vera gel which is deposited at room temperature ranges from relatively stable at $\mathrm{pH} 2$, while being stored at cold temperature has increased. An increasing number of acidic or low $\mathrm{pH}$ values during storage is also possible due to microorganism activity which can be a component of carbohydrates convection acid. At $\mathrm{pH}$ too low there will be an awful lot of carboxylic ion-neutral, so no style deny will consequently happen decrease viscosity. Viscosity is a measure of the relative to the movement of the fluid resistance of the parts.

The purpose of warming at $80^{\circ} \mathrm{C}$ is to reduce or suppress the activities of phenolase are very instrumental in the changing nature of the physicochemical immobilization Aloe Vera gel. The longer the warming gel viscosity of the resulting greater. This is because the longer the warm up then the greater the amount of water evaporated. The water that is in the gel immobilization mechanically. The gel has a variation on the degree of hardness, elasticity, and fragility, that it all depends on the type and concentration of the ingredients of the gel-forming, salt content, $\mathrm{pH}$ and temperature. Aloe Vera gel nature unstable and very easily influenced by air, light, heat, and microbes. The longer storage, Aloe Vera gel viscosity decrease. This is because the longer the retention of the greater the chance of fluid out of the three-dimensional structure of the gel, which is highly correlated with a decrease in $\mathrm{pH}$ that occurs in Aloe Vera gel. Liquefaction involves dismantling the cross-bonding gel by involving chains of polymers of carbohydrates [5]. Besides, some gels during storage or release of liberation events show medium dispersed spontaneously even at high humidity and low temperatures. The gel is stored at cold temperatures also experienced a decrease in activity, despite the loss of its activity is getting low. Loss of activity caused by enzymatic activity after separate leaves from the tree. This means although stored on cold temperatures will also cause a loss of biological activity.

Aloe Vera Gel consists of approximately $99.5 \%$ water and $0.5 \%$ solid material composed of a variety of compounds including the compound that is soluble in water and soluble in fats, vitamins, minerals, enzymes, polysaccharides, phenolic compounds and organic acids [6]. From the results obtained that the moisture content of Aloe Vera gel which is deposited at room temperature tend to increase until day 3 and dropped back on day 6 . While the gel is stored at cool temperatures prevail instead.

\subsection{Application of Edible Coating on Strawberry Fruit}

Preservation techniques of fruit and vegetables with the use of edible coating already done a long time ago. On fruits and vegetables, edible coating application is used to reduce the occurrence of loss of moisture, improve appearance, acts as a barrier to the exchange of gases, as well as having functions as an antifungal and antimicrobial. Also, to extend shelf life, an edible coating is widely used because it does not harm human health, can be eaten as well as easy to untangle nature. 
One of the natural ingredients that can be used as an edible coating is Aloe Vera. Aloe Vera useful part is the gel which is obtained from the leaves of the parenchyma tissue section containing compounds such as a complex polysaccharide, glucomannan, reduction of sugar, tannins, organic acids, minerals, proteins and so forth [2]. Aloe Vera gel can create layers, does not affect the taste, safe for the environment, cheap and easy to come by, has a natural structure making it easy to be applied. But the disadvantage is the nature of the gel rheology easily become diluted, so that should be added to maintain the consistency of the gel treatment. This research is expected to generate manufacturing edible coating formulation of the exact Aloe Vera gel so that later can be applied at post-harvest handling process the fruits in the community.

\subsection{Moisture Content of Strawberry Fruit}

Coating is in demand due to the nature of acceptable barrier and structural integrity [8], [9]. The use of the edible coating on fruits with applications on the surface of the fruit pieces aims to provide a modified atmosphere, gas transfer inhibitors, reduce water and aroma loss, delay discoloration, and Improve appearance [10], [16]. From the results of the analysis using costat obtained that treatment type of fillers and their interaction and storage time shows no real difference against variable moisture content. This is likely because all fillers have the same function as a barrier to water vapor and moisture exchanges so that the moisture content of the fruit a lot anyway. Similarly, the storage time of the fruit on the edible coating does much to affect water content of fruit strawberries possibly because edible coating acted only on the surface of the material is not up to the cell network the fruit so that the water levels were relatively constant. The average of moisture content on strawberry can be seen in Figure 1. From the test results indicate that the error Duncan't 3.3689, free 18 degrees with their significance level of 5\%, LSD 1, 8178 shows at the treatment this type of filler materials $(\mathrm{P})$ gliserol $(\mathrm{P} 3)$ has the highest water content then the acid treatment Ascorbic (P1) and lastly potassium sorbate (P2).

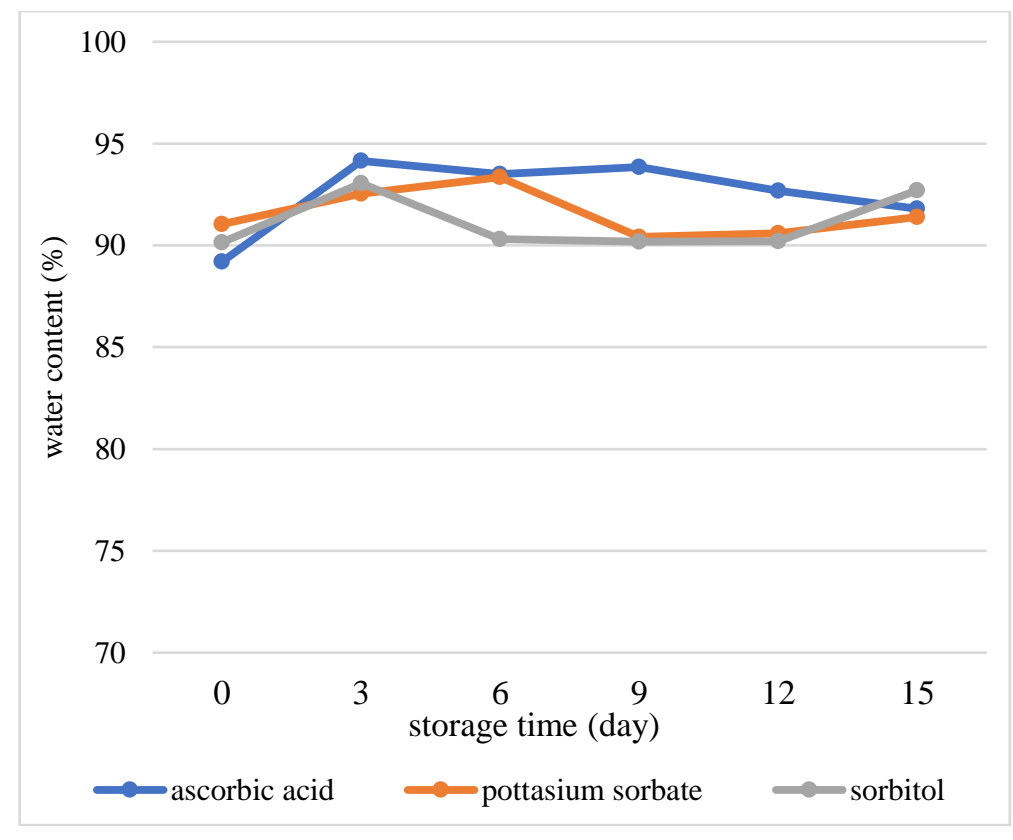

Figure 1

Moistrue Content of Strowberry Fruit 


\subsection{Levels Vitamin C of Strawberry Fruit}

Vitamin $\mathrm{C}$ is one of the nutrients that acts as an antioxidant and effectively addresses free radicals that can damage cells or tissues from oxidative damage inflicted by radiation. Strawberry fruits contain several nutrients which are beneficial for the improvement of people's nutrition. Vitamin $\mathrm{C}$ is one of which highly needed by the body and can be used as a source of which. Vitamin $\mathrm{C}$ level of strawberries is strongly influenced by their varieties, environments, places, fertilizers, maturity levels, and so on. Levels of vitamin $C$ will increase until the fruit is ripe, and will decrease when the maturity level has been exceeded. Statistical analysis obtained that treatment type of fillers, storage time and their interaction show no real difference against the variable levels of vitamin $C$ fruit strawberries. This is likely because all fillers have the same capabilities as an antioxidant and can prevent the exchange period so that the levels of vitamin $\mathrm{C}$ fruit relatively similar. Similarly, the storage time of the fruit on the edible coating does not give different effects against the levels of vitamin $C$ fruit strawberries. This is possible because edible coating acted on the surface of the fruit as a barrier/barrier not to enter into the cell network so that the fruit does not contact with oxygen so that the oxidation process of Ascorbic acid can be avoided. With levels of vitamin $\mathrm{C}$ is relatively constant. From the test results indicate that the error Duncan't 11, 3241, 18 free degrees with their significance level of 5\%, LSD showed at the treatment 3.33337 types of filler materials $(\mathrm{P})$ ascorbic acid (P1) have the highest levels of vitamin $\mathrm{C}$ then the treatment potassium sorbate (P2) and gliserol (P1).

\subsection{The texture of Strawberry Fruit}

Texture is the critical characteristic of strawberries for its quality. The hardness of the fruit is crucial. Softhenes fruit is one of the unwanted changes during storage. At biochemical levels, this is due to the insolvent and depolymerization of the polysaccharide cell walls [17]. Kink is an essential factor that affects the quality of the fruit, which relates to the water content. Water affects the physicochemical qualities and food microbiology. The statistical analysis of the data by using a type of treatment fillers, storage time and their interaction suggests the differences are not really against the variable levels of the texture of fruit strawberries. This is likely because all fillers have the same capabilities as a deterrent that is capable of preventing the exchange period so that the composition and the stubbornness of the fruit are relatively fixed. Similarly, the storage time of the fruit does not give different effects against the texture of the fruit of the strawberry.

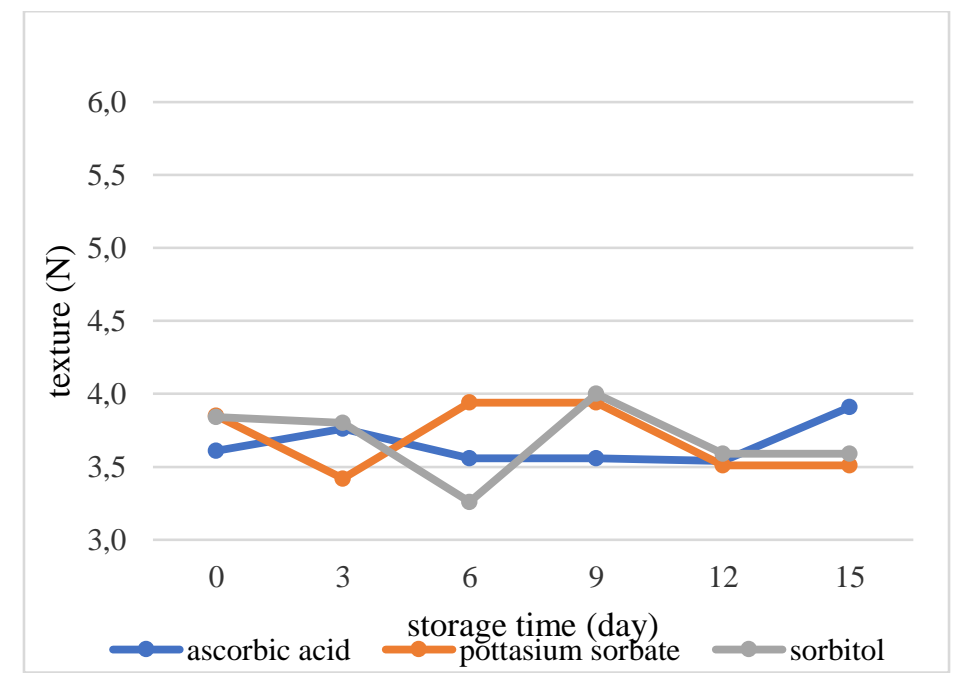

Figure 2

Texture of Strawberry Fruit 
This is possibly because edible coating with different time still have the same capabilities in protecting Strawberry fruit from the process of transpiration, dehydration, oxidation and so forth, so that the water content, bioactive compounds and other components in the network of cells of the fruit and the stubbornness of the fruit until the fruit texture relative constant [14], [15]. From the test results indicate that the error. The average of texture on strawberry can be seen in Figure 2. The treatment type of filler materials (P) sorbitol (P3) has the best texture and then potassium sorbate (P2) and Ascorbic acid (P1).

\subsection{Total Soluble Solid}

Total soluble solid of strawberry fruit has increased during storage, the filer type treatment shows a significant difference. Sorbitol provides the lowest total soluble solid of the strawberry fruit compared to the others. Sugar content of some types of fruits, sometimes it will increase during cell maturity. Many kinds of sugar are found in fruits, but the real sugar content changes only include three kinds of sugar, namely glucose, fructose, and sucrose [11].

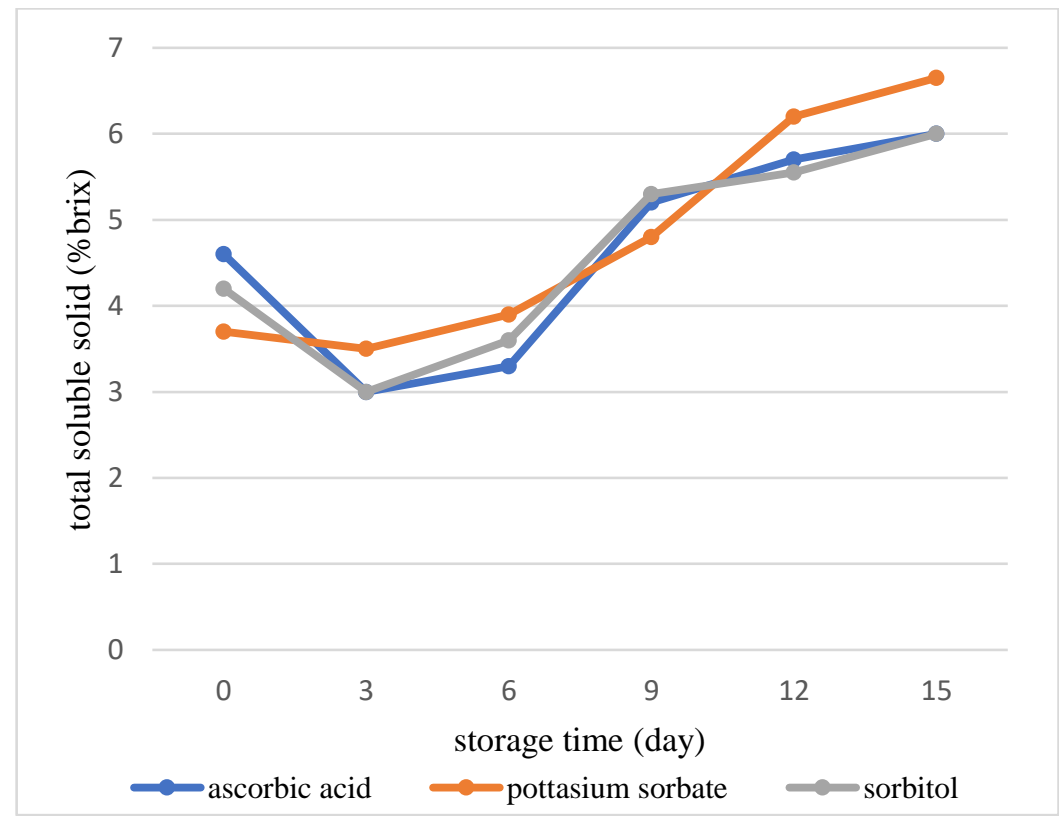

Figure 3

Total Soluble Solid of Strawberry Fruit

\subsection{Weight of strawberry fruit}

According to [11], cold storage influences refrigerated materials, such as losing weight. Loss of fruit weight during storage is mainly caused by water loss, besides this water loss can also reduce quality and inflict damage. Weight of strawberry fruit has decreased during storage; the filer type treatment shows a significant difference. Sorbitol provides the lowest weight loss of the strawberry fruit compared to the others. The weight of fresh fruits and vegetables is caused by the loss of water [12]. [13] reported that the loss of water on Apple increased during storage. Therefore, losing water to strawberries is crucial to the weight of the fruit. Giving sorbitol to prevent heavy shrinkage in the fruit. 


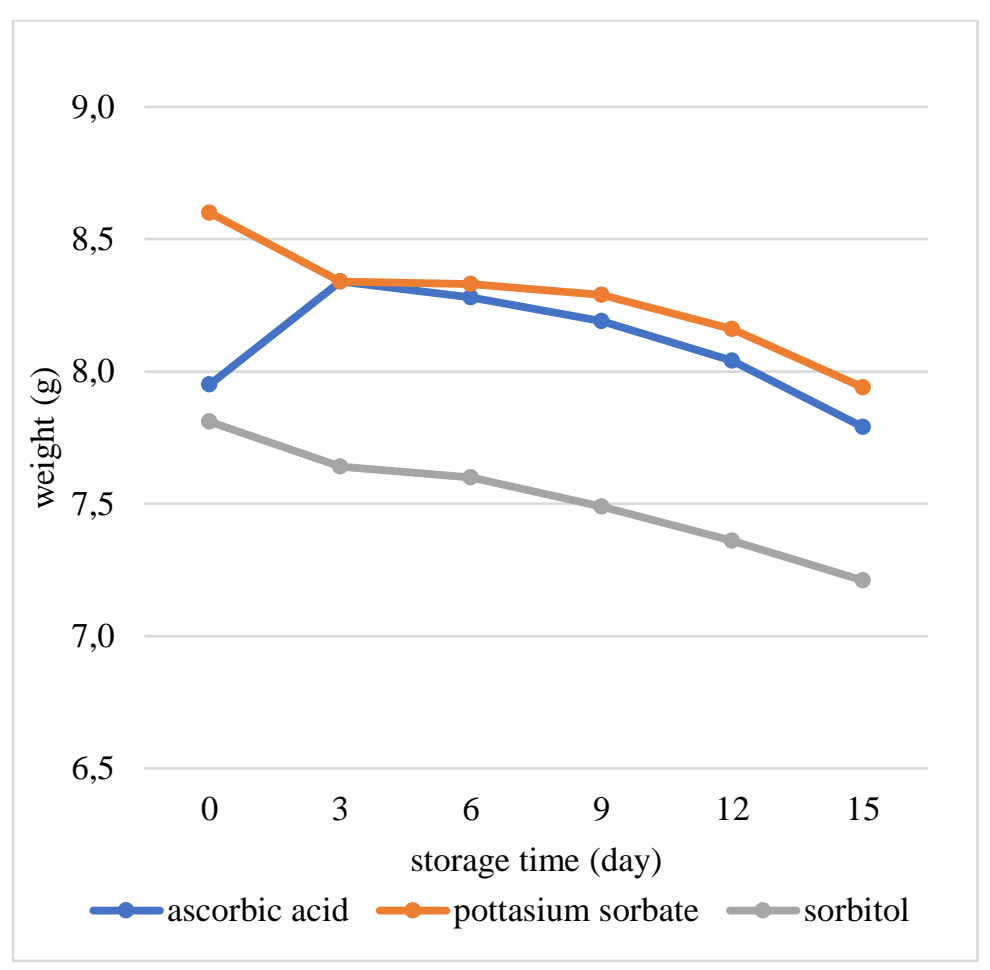

Figure 4

Weight of Strawberry Fruit

\section{Conclusion}

The aloe vera gel with warming and stored at cool temperatures until day 5 relatively stable, as seen from the variable weight shrinkage, color, $\mathrm{pH}$, viscosity and moisture content. While the gel is stored at room temperature decrease began day 2. Aloe Vera gel should be stored at cool temperatures with a sealed container. The best characteristics of Aloe Vera gel that treatment with sorbitol can extend the shelf life strawberry fruit. edible coating base on Aloe gel can be applied at post-harvest handling fruits. Further research needs to be done about the combination of filler with higher concentrations as well as the distance between the longer immersion time treatment.

\section{Acknowledgements}

This research was supported by the competitive grant in the scheme of Strategic Research of National Excellency, Directorate General of Higher Education, Republic of Indonesia. The authors are grateful to the Rector and the Head of Research Institute of Warmadewa University in facilitating to get the grant.

\section{References}

[1] Suriati L, Utama I M S, Harjosuwono B A \& Gunam I B W. (2020). Stability Aloe Vera Gel as Edible Coating. IOP Conf. Series: Earth and Environmental Science 411 (2020) 012053. doi:10.1088/17551315/411/1/012053.

[2] Suriati L, Mangku I G P \& Rudianta I N. (2018). The characteristics of Aloe vera gel as an edible coating. IOP Conf. Ser.: Earth Environ. Sci. 207 012051. doi:10.1088/1755-1315/207/1/012051

[3] Valverde J M, Valero D, Martínez-Romero D, Guillén F, Castillo S \& Serrano M. (2005). Novel Edible Coating Based on Aloe vera Gel to Maintain Table Grape Quality and Safety. Journal of Agricultural and Food Chemistry. 53: 7807-7813. 
[4] Ramachandra C T \& Rao P S. (2008). Processing of Aloe Vera Leaf Gel: A Review. American Journal of Agricultural and Biological Sciences 3(2): 502-510

[5] Raybaudi-Massilia R M, Mosqueda-Melgar J \& Tapia M S. (2010). Edible coatings as carriers of food additives on fresh-cut fruits and vegetables. Stewart Postharvest Review, 3:3. doi: 10.2212/spr.2010.3.3.

[6] Hamman J H. (2008). Composition and Applications of Aloe vera Leaf Gel. Molecules 13(8): 15991616; doi:10.3390/molecules13081599

[7] He, Qian (2003). Quality and Safety Assurance in The Processing of Aloe vera Gel Juice. Food Control Journal. Vol 16, pp 95-104. [21 Mei 2007]. Foods2. Elsevier Applied Science. London.

[8] Dhall R K. (2013). Advances in edible coatings for fresh fruits and vegetables: a review. Journal: Critical Review Food Science Nutrition, 53(5): 435-450.

[9] Galgano F, Condelli N, Favati F, Di_Bianco V, Perretti G \& Caruso M C. (2015). Biodegradeable packaging and edible coating for fresh-cut fruits and vegetables. Ital. J. Food Sci., 27.

[10] Sanchez-Machado D I, Lopez-Carvantes J, Raquel-Sendon \& Sanches-Silva A. (2016). Aloe vera: ancient knowledge with new frontiers. Trends in Food Science \& Technology, 61: 94-102.

[11] Batista-Silva W, Nascimento V L, Medeiros D B, Nunes-Nesi A, Ribeiro D M, Zsögön A \& Araújo W L. (2020). Modifications in organic acid profiles during fruit development and ripening: correlation or causation? Frontiers in Plant Science, 1: 20.

[12] Zhu X, Wang Q, Cao J \& Jiang W. (2008). Effects of chitosan coating on postharvest quality of mango (Mangifera indica L. CV. Tainong) fruits. Journal of Food Processing and Preservation, 32(5): $770-784$.

[13] Cárcel J A, Benedito J, Rosselló C \& Mulet A. (2007). Influence of ultrasound intensity on mass transfer in apple immersed in a sucrose solution. Journal of Food Engineering, 78(2): 472-479. DOI: 10.1016/ j.jfoodeng.2005.10.018

[14] Rahman S, Carter P \& Bhattarai N. (2017). Aloe Vera for Tissue Engineering Applications. Department of Chemical, Biological and Bioengineering, North Carolina A\&T State University, Greensboro, NC 27411, USA.

[15] Suriati L \& Utama I M S. (2019). Characteristics Fillet of Aloe vera Gel as Edible Coating, IOP Conf. Ser.: Earth Environ. Sci. 1402 066021, doi: 10.1088/1742-6596/1402/6/066021.

[16] Chandegara V K \& Varshney A K. 2013. Processing and Products Aloe vera L.: A review., Int. J. Med. Arom. Plants, 3, 492-506.

[17] Moggia C, Graell J, Lara I \& Lobos G A. (2017). Firmness at Harvest Impacts Postharvest Fruit Softening and Internal Browning Development in Mechanically Damaged and Non-damaged Highbush Blueberries (Vaccinium corymbosum L.), Frontiers in Plant Science 8(782): 535. DOI: 10.3389/fpls.2017.00535 